\title{
A microbolometer-based far infrared radiometer to study thin ice clouds in the Arctic
}

\author{
Quentin Libois ${ }^{1}$, Christian Proulx $^{2}$, Liviu Ivanescu $^{1}$, Laurence Coursol $^{1}$, Ludovick S. Pelletier ${ }^{1}$, Yacine Bouzid ${ }^{1}$, \\ Francesco Barbero $^{1}$, Éric Girard ${ }^{1}$, and Jean-Pierre Blanchet ${ }^{1}$ \\ ${ }^{1}$ ESCER Centre, Department of Earth and Atmospheric Sciences, Université du Québec à Montréal (UQAM), \\ Montréal, Canada \\ ${ }^{2}$ Institut National d’Optique (INO), 2740 Einstein Street, Québec City, QC G1P 4S4, Canada \\ Correspondence to: Q. Libois (libois.quentin@uqam.ca)
}

Received: 4 December 2015 - Published in Atmos. Meas. Tech. Discuss.: 18 January 2016

Revised: 30 March 2016 - Accepted: 8 April 2016 - Published: 27 April 2016

\begin{abstract}
A far infrared radiometer (FIRR) dedicated to measuring radiation emitted by clear and cloudy atmospheres was developed in the framework of the Thin Ice Clouds in Far InfraRed Experiment (TICFIRE) technology demonstration satellite project. The FIRR detector is an array of $80 \times 60$ uncooled microbolometers coated with gold black to enhance the absorptivity and responsivity. A filter wheel is used to select atmospheric radiation in nine spectral bands ranging from 8 to $50 \mu \mathrm{m}$. Calibrated radiances are obtained using two well-calibrated blackbodies. Images are acquired at a frame rate of $120 \mathrm{~Hz}$, and temporally averaged to reduce electronic noise. A complete measurement sequence takes about $120 \mathrm{~s}$. With a field of view of $6^{\circ}$, the FIRR is not intended to be an imager. Hence spatial average is computed over 193 illuminated pixels to increase the signal-to-noise ratio and consequently the detector resolution. This results in an improvement by a factor of 5 compared to individual pixel measurements. Another threefold increase in resolution is obtained using 193 non-illuminated pixels to remove correlated electronic noise, leading an overall resolution of approximately $0.015 \mathrm{~W} \mathrm{~m}^{-2} \mathrm{sr}^{-1}$. Laboratory measurements performed on well-known targets suggest an absolute accuracy close to $0.02 \mathrm{~W} \mathrm{~m}^{-2} \mathrm{sr}^{-1}$, which ensures atmospheric radiance is retrieved with an accuracy better than $1 \%$. Preliminary in situ experiments performed from the ground in winter and in summer on clear and cloudy atmospheres are compared to radiative transfer simulations. They point out the FIRR ability to detect clouds and changes in relative humidity of a few percent in various atmospheric conditions, paving the way
\end{abstract}

for the development of new algorithms dedicated to ice cloud characterization and water vapor retrieval.

\section{Introduction}

During the Arctic polar night, the energy budget of the surface and atmosphere are mainly governed by long-wave radiative fluxes (Overland et al., 1997). Of uttermost importance is the far-infrared (F-IR) spectral region $(\lambda>15 \mu \mathrm{m})$, from which approximately $40 \%$ of the energy escaping the Earth originates (Harries et al., 2008), and where more than $60 \%$ of the atmospheric cooling of the dry and cold Arctic atmosphere occurs (Clough et al., 1992). A refined comprehension of the Arctic climate thus requires a thorough understanding of the radiative properties of the atmosphere in the F-IR. It is well established that these radiative properties are highly sensitive to the amount of water vapor (Turner and Mlawer, 2010; Bianchini et al., 2011) and to the physical properties of clouds (Curry, 1983; Maestri et al., 2014). However, these two major components of the hydrological cycle and their radiative contributions remain poorly known in the Arctic winter. The radiative processes at stake are indeed complex and still constitute active fields of research (Yang et al., 2005; Palchetti et al., 2008; Delamere et al., 2010; Turner et al., 2012). In addition, accurate measurement of humidity and cloud properties during the polar night is difficult (Cimini et al., 2009; Eastman and Warren, 2010; Blanchard et al., 2014). For instance, decadal cloud cover trends are uncertain and the negative trend observed by Wang (2003) 
using satellite data was not confirmed by surface observation reported by Eastman and Warren (2010). The recent deployment of satellites dedicated to clouds remote sensing, e.g., CALIPSO (Winker et al., 2003) and CloudSat (Stephens et al., 2002), has nevertheless filled a gap in clouds' observations at high latitudes (Delanoë and Hogan, 2010). It has, in particular, highlighted the ubiquity of thin ice clouds (TICs) barely visible before (Grenier et al., 2009).

Although these TICs are characterized by small optical thickness $(\leq 5)$, they have a critical radiative impact. They indeed act as atmospheric radiators and their cooling efficiency is very sensitive to their microphysical properties (Curry et al., 1996). If ice crystals become large enough to precipitate, this dehydrates the atmosphere, which reduces the latter opacity and cools down the surface and consequently the lower troposphere. This process, coined dehydration greenhouse feedback by Blanchet and Girard (1994), has the potential to further cool the atmosphere and surface (Blanchet and Girard, 1995). This provided a potential explanation for the observed negative trend in Arctic surface temperatures observed in the late twentieth century (Comiso, 2003; Wang, 2003). The latter indeed remained unexplained by climate simulations which predicted a persistent warming during winter due to the increase in anthropogenic greenhouse gases (Kahl et al., 1993). The radiative impact of precipitating clouds raised the need to study the TICs in more detail (Jouan et al., 2012), and the F-IR proved to be a good candidate to observe those clouds (Blanchard, 2011) and discriminate between precipitating and non-precipitating ones (Yang, 2003; Blanchard et al., 2009). Such F-IR observations have already been used to study TIC at Eureka in the Arctic (Mariani et al., 2012) and at Dome C in Antarctica (Palchetti et al., 2015).

With the intent to further investigate TICs' formation and characteristics in the Arctic, a satellite project sponsored by the Canadian Space Agency was initiated. The Thin Ice Clouds in Far InfraRed Experiment (TICFIRE) mission (Blanchet et al., 2011) aims to fill a gap in remote sensing observation of the Earth in the F-IR range (e.g., Maestri et al., 2014), with a special focus on TICs and water vapor in the polar regions. The objective is to have a global picture of TICs and explore the impact of anthropogenic pollution on their physical properties (Grenier and Blanchet, 2010). This recent interest for the F-IR, largely fostered by technology developments, gave rise to other satellite projects such as REFIR (Radiation Explorer in the Far InfraRed) (Palchetti et al., 1999, 2006) and CLARREO (Climate Absolute Radiance and Refractory Observatory) (Taylor et al., 2010). While many recent developments in the F-IR have chosen the use of interferometers to get a hyperspectral picture of the Earth (e.g., Canas et al., 1997; Knuteson et al., 2004; Rochette et al., 2009; Bianchini and Palchetti, 2011), the TICFIRE detector will be an uncooled microbolometer-based imaging radiometer. This choice is consistent with the constrained budget of the mission, with the emphasis put on ob- taining two-dimensional (2-D) images of the clouds and radiance measurements.

On the way towards the TICFIRE mission, a breadboard has been developed to serve as a first experimental platform to highlight the potential of the future satellite mission. Here we present the far infrared radiometer (FIRR) prototype designed to measure radiation in nine spectral bands ranging from 8 to $50 \mu \mathrm{m}$. The FIRR aims to demonstrate the capability of a microbolometer-based radiometer to accurately measure F-IR radiation. The design and data acquisition procedure of the instrument are detailed in Sect. 2. Its radiometric performances are investigated in Sect. 3 and preliminary upward-looking measurements taken on cloudy and clearsky scenes are presented in Sect. 4. These results are then discussed with regards to the TICFIRE mission requirements (Sect. 5).

\section{Instrument design and data acquisition}

This section presents the technical characteristics of the FIRR and the data acquisition procedure. The calibration algorithm used to convert raw measurements into calibrated radiance is also detailed.

\subsection{Instrument design}

The general principle of the FIRR is to measure radiation coming from the atmosphere, then to compare it to radiation measured on two calibration blackbodies (BBs) to deduce absolute atmospheric radiance (e.g., Shaw et al., 2005). Practically, the FIRR is made up of two separate devices that are electronically connected. The optomechanical device (OMD, Fig. 1a), essentially comprises the scene selection mirror (hereinafter referred to as SSM), the BBs and the optics enclosure (Fig. 1b) which hosts the filter wheel assembly, the telescope and the detector. The instrument control device (ICD) contains most electronic components, the embedded computer controlling the complete system through a dedicated software and a hardware control panel. The FIRR design is compatible with both ground measurements and airborne operation.

\subsubsection{Optomechanical device (OMD)}

The FIRR has two viewing ports, allowing up- and downlooking measurements with a field of view of $6^{\circ}$. Radiation coming from either direction or from the BBs is relayed to a filter wheel by a gold coated rotating mirror driven by a step motor (the SSM). The calibration enclosure containing the BBs and SSM is very similar in design to the Atmospheric Emitted Radiance Interferometer (AERI) (Knuteson et al., 2004) and the Atmospheric Sounder Spectrometer for Infrared Spectral Technology (ASSIST) (Rochette et al., 2009) instruments. The BB design has been thoroughly validated by the Space Science and Engineering Center (SSEC) group 
(a)
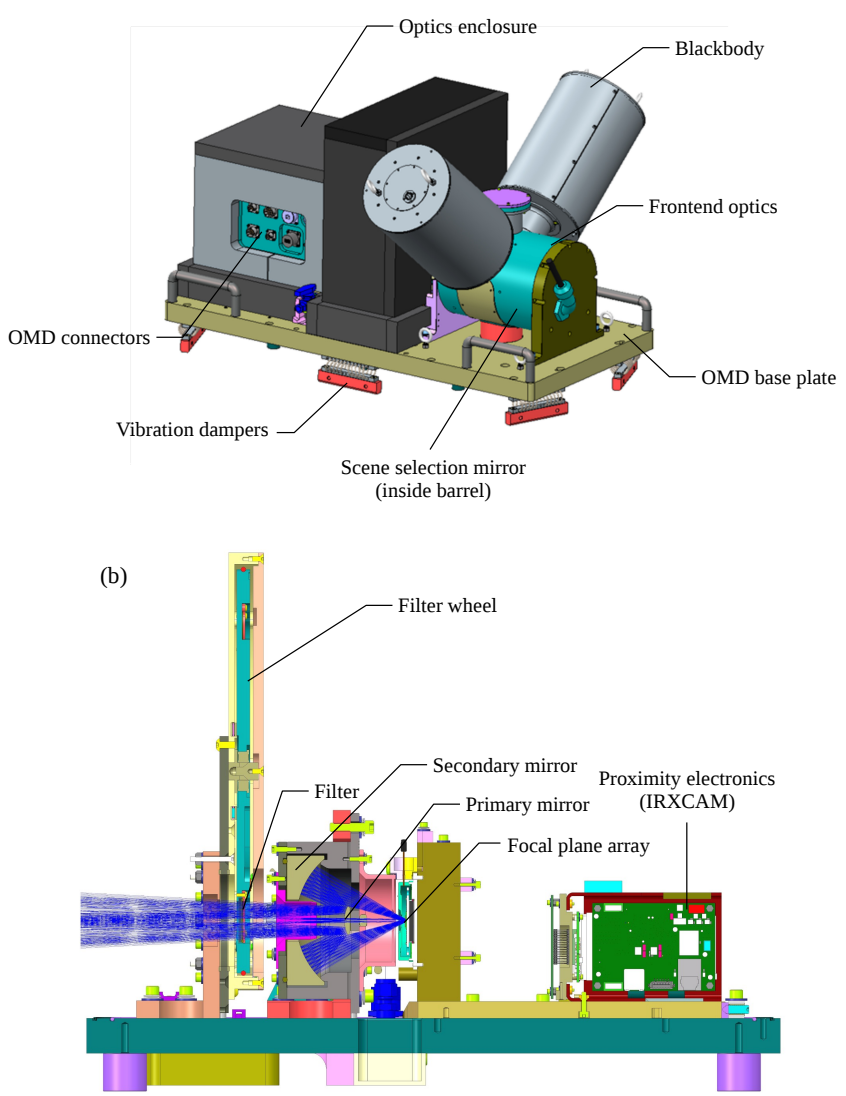

Figure 1. (a) Overview of the FIRR optomechanical device. The base plate dimensions are $90 \times 44 \mathrm{~cm}$. (b) Section view of the optics enclosure.

at the University of Wisconsin (Best et al., 2003). The spectral reflectance of Z306 paint samples similar to the BBs' inner coating was measured by Surface Optics Corp. in the spectral range of the FIRR, from which the BB emissivity was deduced. The BBs' temperature can be controlled from -30 to $60^{\circ} \mathrm{C}$ with $5 \mathrm{mK}$ accuracy (Rochette et al., 2009). It can not be set at a temperature below the ambient temperature, though, because the BBs can only be heated. Potential deterioration of the calibration unit will be investigated based on a yearly check up of the BBs emissivity and temperature sensors.

The motorized filter wheel is used to select the spectral channel to be measured. It currently hosts nine $1.25 \mathrm{in}$. diameter filters, as well as an opaque position and an open position, the last two positions being essentially used to investigate the thermal behavior of the filters and calibration enclosure. Six more positions are available on the wheel but are currently unused. All filters are interference filters except for the $30-50 \mu \mathrm{m}$ filter that is a mesh filter. These filters were custom-made by four different companies experienced in satellite applications (e.g., McCleese et al., 2007). Their
Table 1. Filters spectral characteristics.

\begin{tabular}{lrll}
\hline $\begin{array}{l}\text { Band } \\
\text { number }\end{array}$ & $\begin{array}{r}\text { Spectral range } \\
(\mu \mathrm{m})\end{array}$ & Substrate material & Supplier \\
\hline 1 & $7.9-9.5$ & Zinc sulfide & Infrared Filters Solutions \\
2 & $10-12$ & Zinc sulfide & Infrared Filters Solutions \\
3 & $12-14$ & Zinc selenium & Reynard Corporation \\
4 & $17-18.5$ & Cadmium telluride & University of Reading \\
5 & $18.5-20.5$ & Cadmium telluride & University of Reading \\
6 & $17.25-19.75$ & Cadmium telluride & University of Reading \\
7 & $20.5-22.5$ & Cadmium telluride & University of Reading \\
8 & $22.5-27.5$ & Cadmium telluride & Infrared Filters Solutions \\
9 & $30-50$ & - & QMC Instruments \\
\hline
\end{tabular}

spectral characteristics is the result of a trade between the user's requirements and technological limitations. The objective was to cover the spectral range from 8 to $50 \mu \mathrm{m}$ as much as possible, while ensuring that a sufficient amount of radiation lies in each band. The transmittances of all filters were measured in the laboratory and are shown in Fig. 2a. Their spectral characteristics, the materials used for the substrate of the interference filters and the suppliers' references are summarized in Table 1. The narrow field of view of the FIRR ensures near-normal incidence on the filters, which is beneficial to the angular uniformity of the transmittance. In order to illustrate the sensitivity of FIRR spectral bands to water vapor, Fig. $2 \mathrm{~b}$ shows the transmittance of the atmosphere in those bands as a function of column water vapor.

The filtered radiation is relayed to the detector via a telescope based on a Schwarzschild configuration with two onaxis spherical mirrors. The use of reflective optical elements with an appropriate coating ensures high and uniform transmittance over all the spectral bands of the FIRR. The use of aluminium mirrors also ensures stability of the design with varying temperature. The system has an $f$ number of 1.12 . The detector positioned at the focal plane of the telescope is a 2 -D array $(80 \times 60$ pixels $)$ of $104 \mu \mathrm{m}$ pitch uncooled microbolometers developed at Institut National d'Optique (INO), similar to those used for the EarthCARE mission broadband radiometer (Wallace et al., 2009; Proulx et al., 2009). The pixels are coated with gold black to enhance absorbance and responsivity (Ngo Phong et al., 2015). The detector is embedded in a vacuum-sealable INO GEN5 package sealed by a chemical vapor deposition diamond window to ensure broadband uniform transmittance of the signal to the detector. It is operated at $15^{\circ} \mathrm{C}$, which offers the best compromise between detector sensitivity and thermal noise (both decreasing with temperature). Based on the telescope design, a circular-shaped array of $\sim 300$ pixels $(\sim 2.1 \mathrm{~mm}$ diameter) has an adequately unobstructed view of the scene with homogeneous illumination. Nevertheless, to avoid any edge effects, only 193 pixels are actually used in this study. The detector signal is recorded by the INO IRXCAM camera at $120 \mathrm{~Hz}$.

The optics enclosure contains heaters and thermometers to ensure temperature control and stability during operation, 

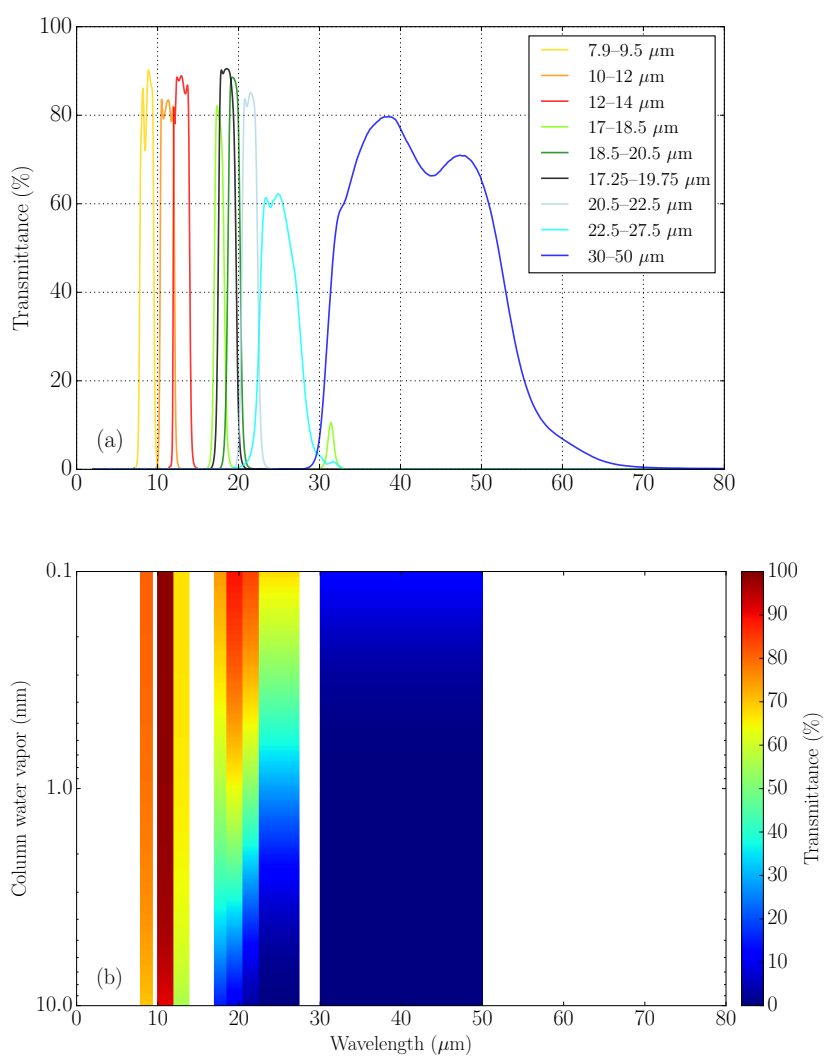

Figure 2. (a) Spectral transmittance of the nine filters of the FIRR. (b) Atmospheric transmittance of the standard subarctic winter atmosphere in the bands of the FIRR as a function of column water vapor, as calculated with MODTRAN. For the sake of clarity, the band $17.25-19.75 \mu \mathrm{m}$ is not shown because it overlaps with other bands.

which is a prerequisite to achieve optimal radiometric accuracy. Temperature and relative humidity in the calibration enclosure are monitored as well. The OMD temperature is stabilized at $15{ }^{\circ} \mathrm{C}$ to match detector temperature. When ambient temperature is above this value, the OMD temperature increases because cooling is not possible.

\subsubsection{Instrument control device (ICD)}

The ICD consists of an electronics rack that contains the BBs' controller, the instrument temperature regulation system and the embedded computer. The latter hosts dedicated software that allows manual and automatic measurements. The system can be powered by a standard $110 \mathrm{~V} / 60 \mathrm{~Hz}$ supply power or from a $28 \mathrm{~V}$ derivative current for use on board an aircraft.

\subsection{Data acquisition and processing}

\subsubsection{Data format}

A single FIRR measurement consists in a series of frames acquired at fixed SSM and filter wheel positions. It is stored in a raw file containing the 16 bit numeric counts of all single frames and their corresponding times of acquisition, as well as a header recording the SSM and filter wheel positions. The FIRR can be operated in manual or automatic mode. In manual mode, the position of the SSM and that of the filter wheel are user-supplied and the number of frames to be taken has to be provided. In automatic mode, the sequence of measurements to be taken is written in an input file. All measurements taken in one sequence are stored in a single directory. The temperature and humidity records acquired during the sequence, as well as the camera and BBs' parameters, are stored in this same directory. An automatic sequence can be repeated in a loop as many times as desired.

\subsubsection{Instrument operation}

FIRR measurements can be acquired following two different modes: the "fast" and the "slow" sequences. For the fast sequence, the SSM is fixed on a position and the filter wheel is rotated to illuminate consecutively all filters. This is repeated for the two calibration BBs and then for the scene. For the slow sequence, the filter wheel position is maintained and the SSM is rotated to view the BBs and the scene consecutively. This is repeated for all filters. Since the rotation of the SSM takes approximately $7 \mathrm{~s}$, whereas rotating the filter wheel takes about $1 \mathrm{~s}$, the fast sequence, which minimizes the number of mirror rotations, is approximately 2.5 times faster than the slow one. In nominal conditions (one scene view, 11 filter wheel positions and 100 frames), the fast sequence takes $2 \mathrm{~min}$ and the slow $5 \mathrm{~min}$.

Both sequences have advantages and drawbacks. The fast sequence is best suited when scene variations are expected at timescales of a few minutes, first because its higher sampling rate allows a better detection of such variations, and second because all scene measurements are taken in an approximate $45 \mathrm{~s}$ interval. Comparatively, the scene measurements are taken throughout the $5 \mathrm{~min}$ of the slow sequence, making it difficult to compare different spectral bands in case of scene variations. In terms of calibration quality, the slow sequence is better because it minimizes the time interval between scene measurement and calibration for a given filter. Conversely, there is an approximate $45 \mathrm{~s}$ between scene measurement and calibration for the fast sequence, which is sufficient for the background signal to change significantly in case of variable OMD temperature. In this case, the background temporal variation must be handled adequately (Sect. 2.2.3). Eventually, when the temperature of the calibration enclosure significantly differs from that of the OMD, the filter temperature can change when it lies on the optical path. This tempera- 
ture change is minor for the fast sequence because the filter remains only a few seconds facing the calibration enclosure. On the contrary, this temperature change and the corresponding variations in the filter self-emission can become significant for the slow sequence because the filter remains in measurement position much longer. This contribution can not be accurately estimated because the radiative temperature of the filter is unknown, and it can not be removed by the calibration procedure, making it particularly critical. To summarize, the fast sequence is more suited for ground-based measurements of cloudy scenes or aircraft measurements. The slow sequence is appropriate for stable atmospheric conditions at temperature near FIRR internal temperature and laboratory experiments with a well-controlled environment.

\subsubsection{Calibration}

The FIRR detector collects radiation from the scene, but also from all the emitting parts of the instrument which are in its field of view (e.g., Montanaro et al., 2014). When cold targets like ice clouds are measured, the signal coming from the scene usually corresponds to only a few percent of the total signal. To compute the true radiance of the scene from the total signal, a two-point calibration is used. It assumes that the total signal $C$ is the sum of a background signal $B$ and a scene signal $S$ (Revercomb et al., 1988). The main assumption is that the scene signal is proportional to the scene radiance $L^{\text {scene }}$. It implies that for each spectral band, the optical transfer function of the FIRR (from SSM to detector package window) and the response of the detector be linear with incident radiance. The first condition is fulfilled by the system and the second is evaluated in details in Sect. 3.2. Under these conditions, the raw signal $C_{i, \lambda}^{\text {scene }}$ for each pixel $i$ and each spectral band $\lambda$ can be written as follows:

$C_{i, \lambda}^{\text {scene }}=B_{i, \lambda}+G_{i, \lambda} L_{\lambda}^{\text {scene }}$,

where $C_{i, \lambda}^{\text {scene }}$ is the average count over all frames. To determine the background signal $B_{i, \lambda}$ and gain $G_{i, \lambda}$, measurements are taken on two sources with known spectral radiance, namely a hot and an ambient $\mathrm{BB}$ (HBB and $\mathrm{ABB}$ ). For the calibration BBs, Eq. (1) reads

$C_{i, \lambda}^{\mathrm{ABB}}=B_{i, \lambda}+G_{i, \lambda} L_{\lambda}^{\mathrm{ABB}}$
$C_{i, \lambda}^{\mathrm{HBB}}=B_{i, \lambda}+G_{i, \lambda} L_{\lambda}^{\mathrm{HBB}}$.

The BBs' radiances are computed after the Planck function using BBs' temperatures and spectral emissivities, as well as the temperature within the BBs' enclosure since it contributes to the measured radiance. The radiance in each spectral band $L_{\lambda}^{\mathrm{BB}}$ is obtained from the convolution of the $\mathrm{BB}$ radiance by the filter normalized spectral transmittance. The background signal and gain are then computed as
$G_{i, \lambda}=\frac{C_{i, \lambda}^{\mathrm{ABB}}-C_{i, \lambda}^{\mathrm{HBB}}}{L_{\lambda}^{\mathrm{ABB}}-L_{\lambda}^{\mathrm{HBB}}}$

$B_{i, \lambda}=\frac{C_{i, \lambda}^{\mathrm{HBB}} L_{\lambda}^{\mathrm{ABB}}-C_{i, \lambda}^{\mathrm{ABB}} L_{\lambda}^{\mathrm{HBB}}}{L_{\lambda}^{\mathrm{ABB}}-L_{\lambda}^{\mathrm{HBB}}}$.

Figure 3 shows typical 2-D maps of gain and background signal retrieved from Eq. (3). The background signal shows a strong spatial gradient inherent to the array fabrication process. The gain pattern does not show such a gradient. Since the radiance in a single band is generally within 5$25 \mathrm{~W} \mathrm{~m}^{-2} \mathrm{sr}^{-1}$, the signal from the scene generally accounts for only $\sim 1 \%$ of the total signal, highlighting the need to remove the background signal properly.

The previous calibration procedure relies on the questionable assumption that the background signal remains constant throughout a sequence. In fact, the background is characterized by low frequency variations that can be linked to $1 / f$ noise of the detector pixels and temperature change of surfaces seen by the detector outside of the scene. These variations can be significant when the fast sequence is used but are less so in the case of the slow sequence, as the time required to see the BBs and scene for a given filter is shorter in the latter case. Thorough investigation of background variations also pointed out the existence of correlated noise sources in addition to random signal variations typical of Johnson noise. These higher frequency variations may be the signature of detector temperature change (thermoelectric cooler controller) and electronic noise, and appear to be similar for all pixels. Hence, a non-illuminated area of pixels is defined (Fig. 3), so that a non-illuminated pixel is associated with each illuminated pixel. The difference between the illuminated and non-illuminated signals is computed for each illuminated pixel to remove part of the correlated noise and obtain corrected raw data:

$$
\begin{aligned}
& C_{i, \lambda}^{\text {scene,ill }}=B_{i, \lambda}^{0}+B_{\lambda}^{1}+G_{i, \lambda} L_{\lambda}^{\text {scene }} \\
& C_{j, \lambda}^{\text {scene,non-ill }}=B_{j, \lambda}^{0}+B_{\lambda}^{1} \\
& C_{i, \lambda}^{\text {scene,corr }}=\left[B_{i, \lambda}^{0}-B_{j, \lambda}^{0}\right]+G_{i, \lambda} L_{\lambda}^{\text {scene }},
\end{aligned}
$$

where $B^{0}$ is the slowly varying contribution of the background, $B^{1}$ is the correlated noise and $j$ is the nonilluminated pixel corresponding to the illuminated pixel $i$.

To correct for the low-frequency variations of the background which are critical for the fast sequence, linear time dependence is assumed. Since the rate of change $r$ represents a new unknown, a third equation is used to complement Eq. (2). The next available measurement performed on the $\mathrm{ABB}$ is thus used. The set of calibration equations becomes 

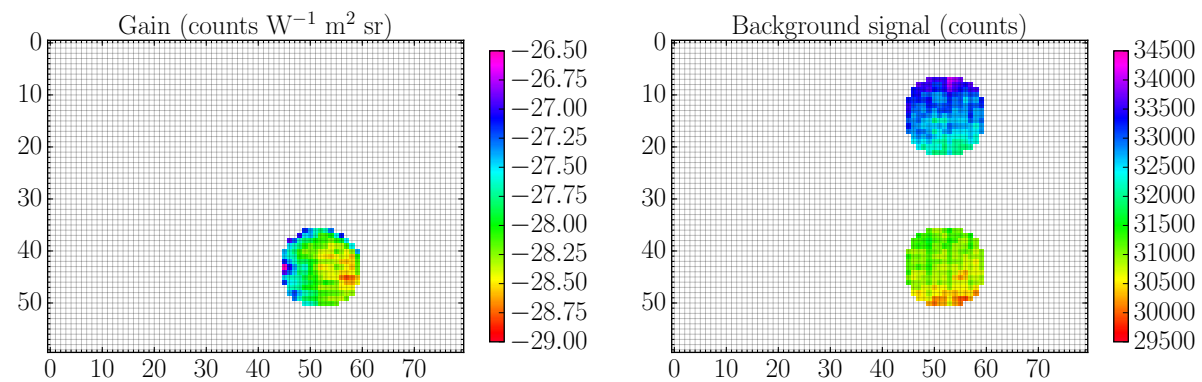

Figure 3. 2-D maps of gain and background signal for filter 7.9-9.5 $\mu \mathrm{m}$ for measurements acquired in the laboratory with $T^{\mathrm{HBB}}=55^{\circ} \mathrm{C}$ and $T^{\mathrm{ABB}}=24.5^{\circ} \mathrm{C}$. Only the 193 pixels used for data analysis are colored. On the right panel, the upper circle shows the non-illuminated area used for the calibration procedure.

$$
\begin{array}{r}
C_{i, \lambda}^{\mathrm{ABB}, \text { corr }}(t)=\left[B_{i, \lambda}^{0}(t)-B_{j, \lambda}^{0}(t)\right]+G_{i, \lambda} L_{\lambda}^{\mathrm{ABB}}(t) \\
C_{i, \lambda}^{\mathrm{HBB}, \operatorname{corr}}\left(t+\Delta t_{1}\right)=\left[B_{i, \lambda}^{0}(t)-B_{j, \lambda}^{0}(t)\right] \\
+r_{i, \lambda} \Delta t_{1}+G_{i, \lambda} L_{\lambda}^{\mathrm{HBB}}\left(t+\Delta t_{1}\right) \\
C_{i, \lambda}^{\mathrm{ABB}, \operatorname{corr}}\left(t+\Delta t_{3}\right)=\left[B_{i, \lambda}^{0}(t)-B_{j, \lambda}^{0}(t)\right] \\
+r_{i, \lambda} \Delta t_{3}+G_{i, \lambda} L_{\lambda}^{\mathrm{ABB}}\left(t+\Delta t_{3}\right),
\end{array}
$$

where $\Delta t_{n}$ is the time lapse with regards to the initial $\mathrm{ABB}$ measurement. The calibrated radiance is eventually computed as

$$
\begin{aligned}
& L_{i, \lambda}^{\text {scene }}\left(t+\Delta t_{2}\right)= \\
& \quad \frac{C_{i, \lambda}^{\text {scene }, \text { corr }}\left(t+\Delta t_{2}\right)-\left[B_{i, \lambda}^{0}(t)-B_{j, \lambda}^{0}(t)\right]+r_{i, \lambda} \Delta t_{2}}{G_{i, \lambda}},
\end{aligned}
$$

where $\Delta t_{2}$ is the time lapse between the ABB and scene measurements.

Contrary to TICFIRE that will have a much larger field of view and significantly different optics, the FIRR is not intended to be used as an imager. Hence the calibrated radiances are averaged over all illuminated pixels, meaning that all pixels are treated equally independently of their responsivity. The averaging procedure can alternatively be performed on the corrected signal before applying the calibration procedure, which is similar to considering the illuminated area as a single large pixel. Since $G$ and $r$ are nearly uniform, Eq. (8) is almost linear and both methods lead to similar results. Here, we use the second averaging method because it is more time-efficient.

\subsubsection{Overall algorithm}

The general workflow used to process the FIRR data in the present study is as follows.

1. For each individual measurement,

a. compute the temporal average and standard deviation over all frames b. select valid pixels with standard deviation less than 2 counts

c. compute the difference between illuminated and non-illuminated pixels for valid pairs

d. compute the 2-D average of the corrected signal.

2. Repeat step 1 for all single measurements of a sequence.

3. Perform calibration to obtain radiances.

It is often convenient to convert radiances into brightness temperatures for the sake of compatibility with other studies and instruments. Here the brightness temperature $T_{B}$ is defined as the temperature that a perfect $\mathrm{BB}$ should have to emit the measured radiance $L_{\lambda}^{\text {scene }}$ in a given band. It is computed as

$\int_{\lambda} \mathcal{T}_{\lambda}\left(\lambda^{\prime}\right) \frac{2 h c^{2}}{\lambda^{\prime 5}} \frac{1}{e^{\frac{h c}{\lambda^{\prime} k_{B} T_{B}}}-1} \mathrm{~d} \lambda^{\prime}=L_{\lambda}^{\text {scene }}$,

where $\mathcal{T}_{\lambda}$ is the normalized transmittance in band $\lambda, \lambda^{\prime}$ is the wavelength, $k_{B}=1.38 \times 10^{-23} \mathrm{~J} \mathrm{~K}^{-1}$ is the Boltzmann constant, $h=6.63 \times 10^{-34} \mathrm{~J} \mathrm{~s}$ is the Planck constant and $c=$ $3.0 \times 10^{8} \mathrm{~m} \mathrm{~s}^{-1}$ is the speed of light in vacuum.

\section{Radiometric characterization}

The radiometric performances of the FIRR, including noise equivalent radiance (NER), measurement repeatability, linearity of the detector and radiometric accuracy, are investigated based on laboratory experiments. For this, the ABB was left at ambient temperature $\left(\sim 25^{\circ} \mathrm{C}\right)$ and the $\mathrm{HBB}$ was set at $55^{\circ} \mathrm{C}$. Two supplementary BBs facing the zenith and nadir ports were used (Fig. 4). These BB cavities are identical to the FIRR calibration BBs. The zenith BB (ZBB) was controlled like the FIRR calibration BBs. The nadir BB (NBB) was immersed in a water-glycol bath, allowing its temperature to be controlled from -27 to $55^{\circ} \mathrm{C}$ at $1 \mathrm{mK}$ resolution. Nitrogen, at the bath temperature, is injected above the NBB to avoid condensation and contamination of the measurements by water vapor. 


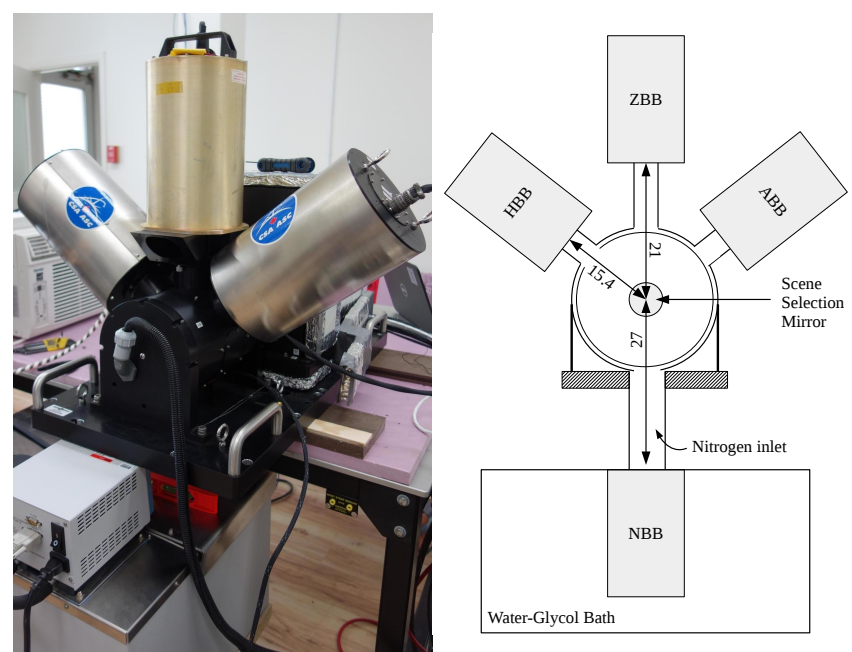

Figure 4. Left: laboratory experimental setup for instrument characterization. The lateral blackbodies are those of the FIRR while that in zenith position was temporarily mounted. The white container at the bottom holds another blackbody immersed in a water-glycol bath regulated by a cryogenic system. Right: schematic front view of the setup. The circle in the middle represents the scene selection mirror. Distances are in centimeters.

\subsection{Instrument resolution}

The detector performances are explored in terms of NER, which is a measurement of its radiometric resolution. NER is given by the ratio of the signal standard deviation over 120 frames $(1 \mathrm{~s})$ to the average gain:

$\operatorname{NER}_{\lambda}=\frac{\sigma_{\lambda}}{G_{\lambda}}$

where $G_{\lambda}$ is computed as

$G_{\lambda}=\left|\frac{C_{\lambda}^{\mathrm{HBB}, \text { corr }}-C_{\lambda}^{\mathrm{ABB}, \text { corr }}}{L_{\lambda}^{\mathrm{HBB}}-L_{\lambda}^{\mathrm{ABB}}}\right|$.

Figure 5a shows the signal standard deviation over 120 frames as a function of the number of illuminated pixels over which the signal is averaged. The standard deviation decreases with the number of pixels used as a result of spatial averaging. It drops to 0.4 counts when 100 pixels are used and reaches approximately 0.28 counts when all the illuminated pixels are used. The standard deviation is practically independent of the spectral band. It also appeared unchanged by the correction with non-illuminated pixels. The gain is shown in Fig. 5b for all spectral bands. It varies from one band to another from -16 to -28 counts $\mathrm{W}^{-1} \mathrm{~m}^{2} \mathrm{sr}$, because the gold black absorbance, hence the responsivity of the detector, is wavelength-dependent (Ngo Phong et al., 2015). In addition, spectral transmittance varies from one filter to another. The $22.5-27.5 \mu \mathrm{m}$ and $30-50 \mu \mathrm{m}$ bands have the lowest transmittances (Fig. 2), which explains the low
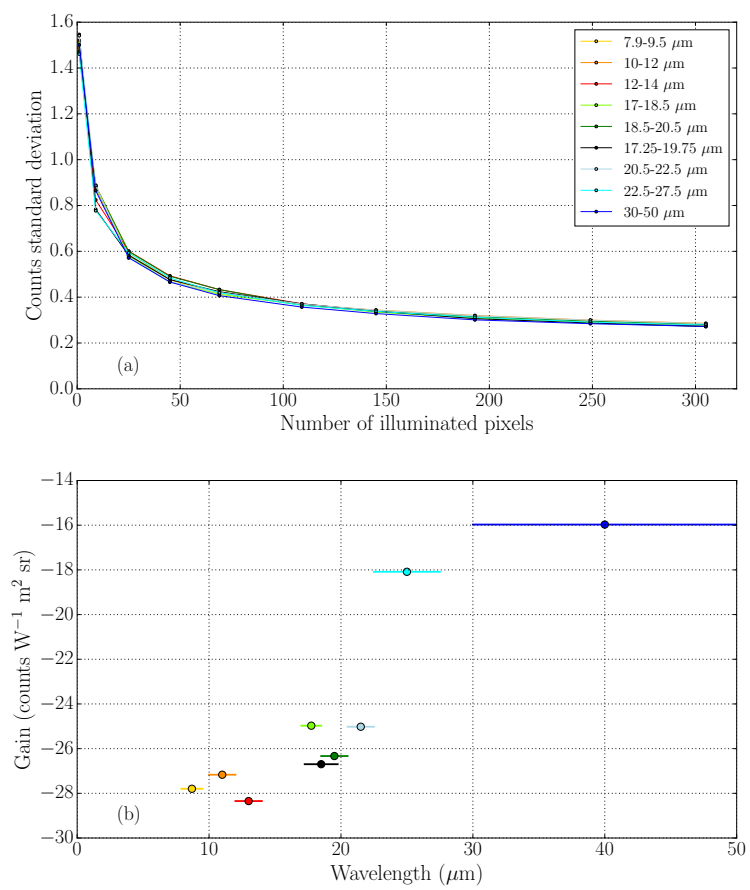

Figure 5. (a) Standard deviation of measurements performed on the $\mathrm{ABB}$ for different illuminated areas. The area is defined as disks around the central pixel. The average over 10 consecutive sequences is shown. (b) Average gain over the same 10 sequences for all bands. Horizontal bars highlight the spectral extent of the bands.

gain absolute values for these bands. As a result, the NER ranges from approximately 0.01 to $0.02 \mathrm{~W} \mathrm{~m}^{-2} \mathrm{sr}^{-1}$ depending on spectral band and number of pixels used. To illustrate the resolution of the FIRR in terms of brightness temperature, the NER is converted into noise equivalent temperature difference (NETD, e.g., Niklaus et al., 2008), that is the temperature increase a perfect BB should experience for its radiance change to equal the NER. Figure 6 shows the variations of NETD with BB temperature for a NER of $0.01 \mathrm{~W} \mathrm{~m}^{-2} \mathrm{sr}^{-1}$. The NETD decreases with temperature, the decrease being more pronounced for thermal infrared ( $\mathrm{T}$ IR, $5 \mu \mathrm{m}<\lambda<15 \mu \mathrm{m}$ ) bands than for F-IR bands. At $20^{\circ} \mathrm{C}$, the NETD ranges from 50 to $200 \mathrm{mK}$, whereas at $-100^{\circ} \mathrm{C}$ it ranges from 200 to $650 \mathrm{mK}$. This is consistent with other radiometric systems (e.g., Legrand et al., 2000). Note that at lowest temperatures, NETD is minimum for F-IR bands because the maximum of the Planck function shifts towards longer wavelengths.

The NER accounts for high-frequency noise at the timescale of one frame but noise also affects the signal at lower frequency. To estimate this lower frequency noise and its impact on the repeatability of the measurements, the difference between the signal acquired on $\mathrm{ABB}$ and $\mathrm{HBB}$ with the 7.9-9.5 $\mu \mathrm{m}$ filter is computed for 40 consecutive sequences, which corresponds to more than $4 \mathrm{~h}$ of measurements. This procedure is performed for corrected and non- 


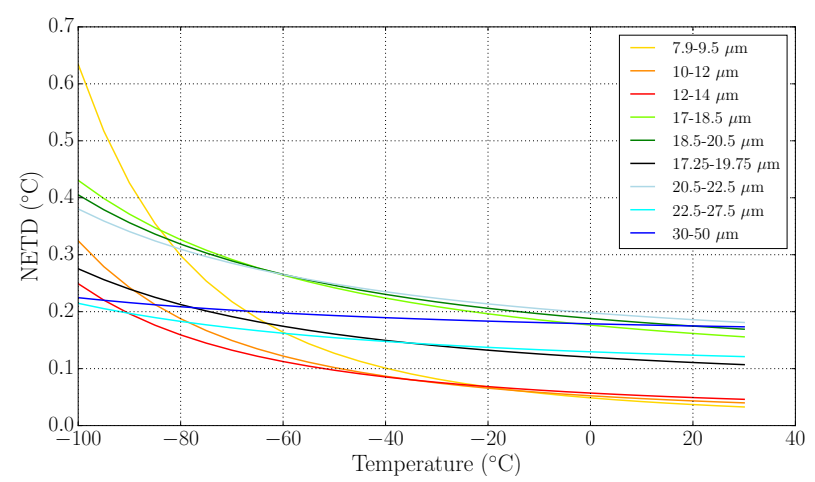

Figure 6. Noise equivalent temperature difference (NETD) corresponding to a noise equivalent radiance (NER) of $0.01 \mathrm{~W} \mathrm{~m}^{-2} \mathrm{sr}^{-1}$, as a function of blackbody temperature for all spectral bands of the FIRR.

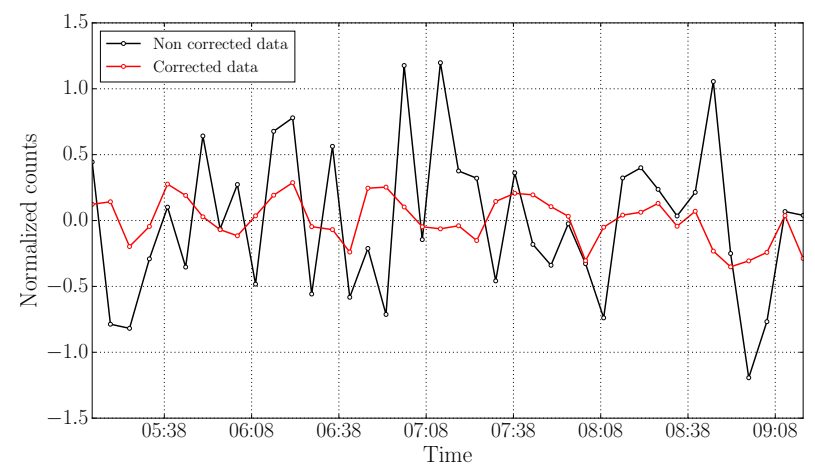

Figure 7. Average counts difference between measurements taken on $\mathrm{ABB}\left(T_{\mathrm{ABB}} \simeq 25^{\circ} \mathrm{C}\right)$ and $\mathrm{HBB}\left(T_{\mathrm{HBB}}=55^{\circ} \mathrm{C}\right)$ through the filter 7.9-9.5 $\mu \mathrm{m}$ for 40 consecutive sequences. The black line was obtained without using the non-illuminated pixels, while the red line corresponds to corrected data. All data were translated to null average for the sake of clarity.

corrected data and the results are shown in Fig. 7. The signal is fairly stable throughout the period of measurements which highlights the thermal stability of the system and BBs over this period. The standard deviation of uncorrected data is 0.57 counts, but it drops to 0.17 counts when the correction is applied. This is less than the standard deviation along 120 frames, which proves the very high repeatability of FIRR measurements and the benefit of using non-illuminated pixels.

To quantify the impact of spatial averaging on FIRR resolution, the same analysis was performed for reduced numbers of illuminated pixels. When a single pixel is used, the standard deviation of the corrected signal is 0.75 counts, but it drops to 0.45 when two pixels are used, and 0.4 when four pixels are used. In view of the TICFIRE imaging application, this proves that spatial averaging over a limited number of pixels could significantly increase the radiomet- ric resolution, even though this would be at the expense of spatial resolution.

\subsection{Instrument linearity}

The two-point calibration procedure (Sect. 2.2.3) relies on the assumption that the contribution of the scene to the total signal delivered by the detector is proportional to the radiance of the source (Eq. 1). To validate this critical assumption, the NBB was used as a well-defined source whose radiance is varied. For this, the temperature of the water-glycol bath was set successively to $-27,-21,-15,-8,0,5,15,35$ and $55^{\circ} \mathrm{C}$, each temperature step lasting $75 \mathrm{~min}$. FIRR measurements were taken continuously using the slow sequence on $\mathrm{ABB}, \mathrm{HBB}$, nadir and zenith views with 200 frames to ensure optimal calibration. The corrected signal was computed for all filters using a restricted illuminated area of 69 pixels. This restriction is necessary because the NBB footprint on the detector is smaller than that of the calibration BB due to its larger distance to the SSM (Fig. 4). For the subsequent analysis, only the measurements taken for sufficiently stable NBB temperature are used. The threshold chosen is such that the standard deviation over $1 \mathrm{~min}$ must be less than $2.5 \mathrm{mK}$. Practically, between 9 and 12 sequences met this criterion at each temperature step. The average NBB spectral radiances are computed for each step. The difference between the average corrected signal on the NBB and HBB is then computed. Since the temperature of the HBB is constant throughout the experiment, this difference is expected to increase linearly with NBB radiance:

$$
C_{\lambda}^{\mathrm{NBB}, \text { corr }}-C_{\lambda}^{\mathrm{HBB}, \text { corr }}=G_{\lambda}\left(L_{\lambda}^{\mathrm{NBB}}-L_{\lambda}^{\mathrm{HBB}}\right) .
$$

Figure 8 shows this difference as a function of NBB radiance. In the temperature range explored, there is no evidence of nonlinearity, which supports the calibration procedure used. The standard deviation over data acquired at the same temperature step ranges from 0.05 to 0.4 counts, which again gives an estimate of the long term stability of the system. The standard deviation of the difference between measurements and the regression line does not exceed 0.03 counts.

\subsection{Instrument accuracy}

The accuracy of the FIRR quantifies its capability to retrieve the absolute radiance of a target, whether the latter is cooler or warmer than both blackbodies or when its temperature lies in between. To this end, the FIRR algorithm is used to retrieve the NBB radiance in the laboratory. Figure 9a shows the difference between retrieved and theoretical radiances for all sequences. The difference does not exceed $0.08 \mathrm{~W} \mathrm{~m}^{-2} \mathrm{sr}^{-1}$, except for the band $30-50 \mu \mathrm{m}$. The latter also exhibits a significant trend, with overestimation of the radiance at temperatures lower than ambient temperature and underestimation beyond. This trend is also observed for the 


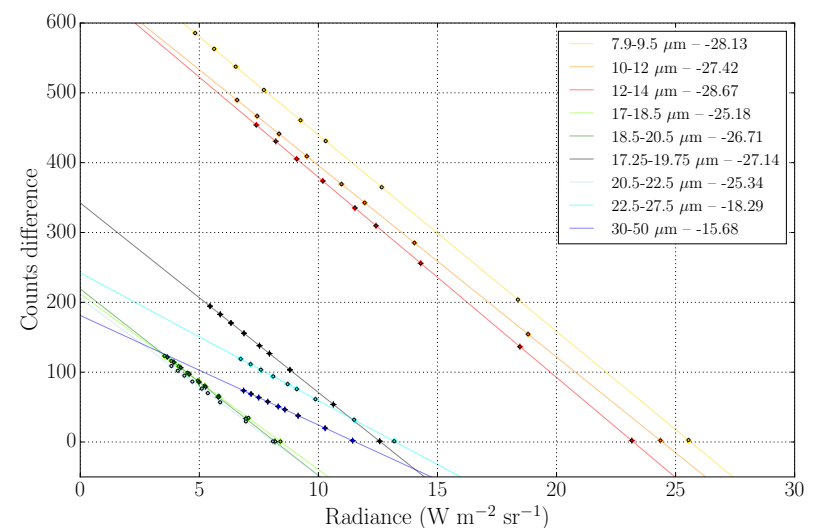

Figure 8. Counts' difference between corrected signals on NBB and HBB in terms of NBB radiance in each spectral band of the FIRR. Dots indicate the average value for each temperature step. The standard deviations among individual measurements are depicted by the error bars. The lines are the linear regressions, whose slopes are indicated in the legend.

other bands, but is less pronounced. We hypothesize that this bias results from the difference in the geometrical positions of the NBB versus the calibration BBs (Mariani et al., 2012). In fact, the difference in optical path results in lower air transmittance from the NBB to the SSM than from the calibration BBs to the SSM, which partly masks the actual temperature of the NBB. Radiative transfer calculations indeed show that the transmittance of $10 \mathrm{~cm}$ of air at $25 \%$ relative humidity and $26^{\circ} \mathrm{C}$ is only $88 \%$ in the band $30-50 \mu \mathrm{m}$ while it is more than $97 \%$ for all the others. To check this hypothesis, the retrieval algorithm is applied to the $\mathrm{ZBB}$, whose distance to the SSM is much closer to that of the calibration BBs and whose temperature varies within $25-55^{\circ} \mathrm{C}$. An illuminated area of 109 pixels is used and Fig. $9 \mathrm{~b}$ shows differences less than $0.02 \mathrm{~W} \mathrm{~m}^{-2} \mathrm{sr}^{-1}$ for most bands, which is very close to the resolution of the FIRR. Since the uncertainty on the theoretical NBB radiance (less than $0.001 \mathrm{~W} \mathrm{~m}^{-2} \mathrm{sr}^{-1}$ ) is much less than the obtained difference, the value $0.02 \mathrm{~W} \mathrm{~m}^{-2} \mathrm{sr}^{-1}$ provides a good estimate of the FIRR accuracy.

\section{Preliminary in situ experiments}

Since the FIRR is aimed at remotely sensing clouds and atmospheric properties such as water vapor content, here three preliminary in situ experiments are presented. Two of them were performed in the core of winter in Québec City (Canada), one at night and the other in daylight conditions. The third experiment was performed during summer in Montréal (Canada). Those measurements are compared to radiative transfer simulations performed with MODTRAN (Berk et al., 1987) in order to assess the FIRR performances and explore its ability to characterize clouds.
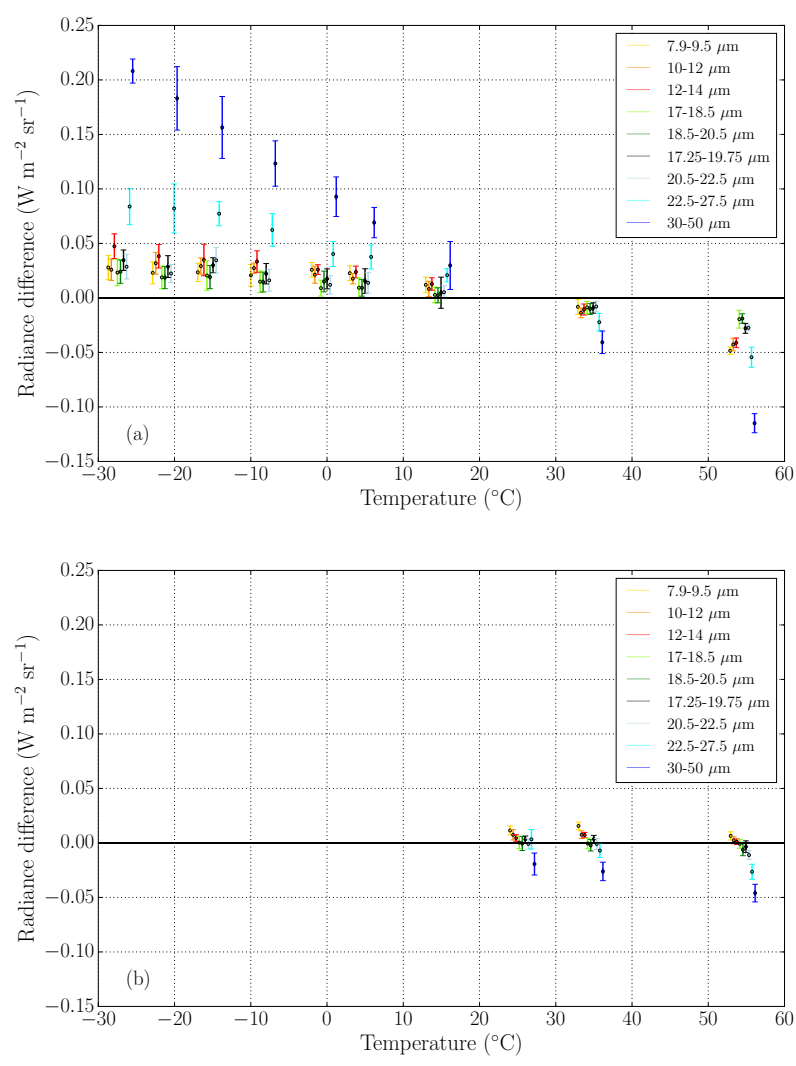

Figure 9. (a) Difference between NBB radiance retrieved with the FIRR algorithm and theoretical radiance for all NBB temperature steps. The error bars show the standard deviation for a given step. Panel (b) depicts the same as (a) but for ZBB radiances.

\subsection{Materials and methods}

\subsubsection{FIRR measurements}

The FIRR measurements were acquired from the ground, using the zenith port of the instrument. The fast sequence was used and all data were acquired with 100 frames per measurement. The first experiment was performed at INO facilities $\left(46.80^{\circ} \mathrm{N}, 71.31^{\circ} \mathrm{W}\right)$ on 21 February 2015 , from 00:27 to 00:50 UTC. The night was extremely clear and the synoptic situation characterized by a well-settled cold front bringing cold polar air (near-surface temperature around $-15^{\circ} \mathrm{C}$ ), so that the conditions were somehow similar to those encountered in early spring in the Arctic. The second experiment was performed on 21 February 2015 from 13:30 to 20:00 UTC, again at INO facilities (Fig. 10), with $2 \mathrm{~m}$ air temperature around $-10^{\circ} \mathrm{C}$. The sky was uniformly overcast in the morning with the solar disc still visible and very light precipitation. The cloud cover progressively vanished from 15:20 to 17:30 with almost clear sky at 16:00. From 18:00, the cloud cover became uniform again and was visually thicker than in the morning. The solar disc was no longer visible. Light precipitation started at 19:45. For these two ex- 


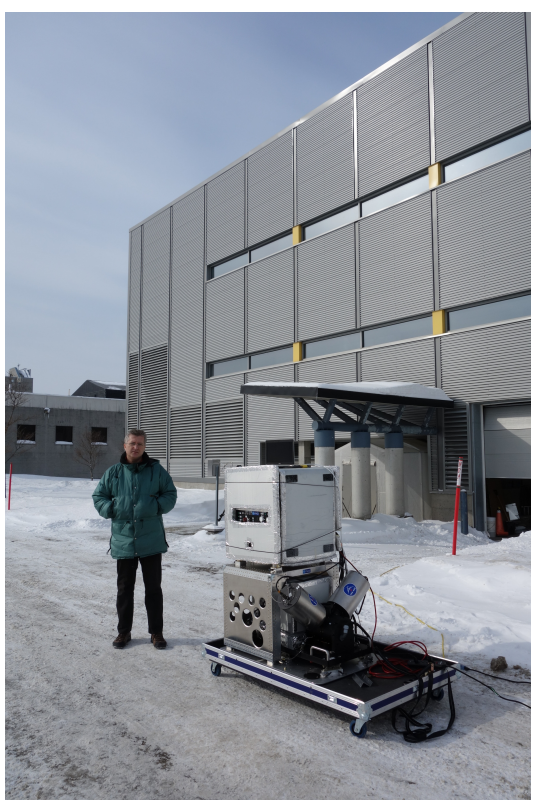

Figure 10. FIRR setup for ground operation at INO facilities on 21 February 2015.

periments, the $\mathrm{ABB}$ and $\mathrm{HBB}$ temperatures were set at 15 and $50^{\circ} \mathrm{C}$. The last experiment was performed on 2 July 2015 on the UQAM campus $\left(45.51^{\circ} \mathrm{N}, 73.56^{\circ} \mathrm{W}\right)$ and lasted $24 \mathrm{~h}$. The air temperature varied between 15 and $25^{\circ} \mathrm{C}$ and relative humidity was around $30 \%$. The $\mathrm{HBB}$ was set at $55^{\circ} \mathrm{C}$ and the $\mathrm{ABB}$ was left uncontrolled at ambient temperature. The sky was mostly clear in the first evening with sparse shallow cumulus appearing occasionally in the field of view of the FIRR. During the night, consistent clouds (most likely stratocumulus) with larger horizontal extension formed and remained from 07:00 to 10:00 UTC. The second day was similar to the previous evening with sporadic occurrence of thin cirrus clouds.

\subsubsection{MODTRAN simulations}

The radiative transfer simulations were performed with MODTRAN v.5.3 (Berk et al., 1987). The vertical profiles of pressure, temperature, humidity and ozone are user-defined. For the winter experiments, these profiles were obtained from the closest 6-hourly ECMWF ERA-Interim reanalyses (Dee et al., 2011). For the summer experiment, the hourly resolution Rapid Update Cycle (RUC) reanalyses from the National Oceanic and Atmospheric Administration (NOAA) (http://ruc.noaa.gov) were used. All other gas concentrations were set to default values for subarctic winter (winter experiments) and midlatitude summer (summer experiment). Background aerosols' concentrations were set to rural values for winter experiments and urban values for the summer experiment. Clouds are defined by a single layer homogeneous in ice and water content, whose optical depth is prescribed. The

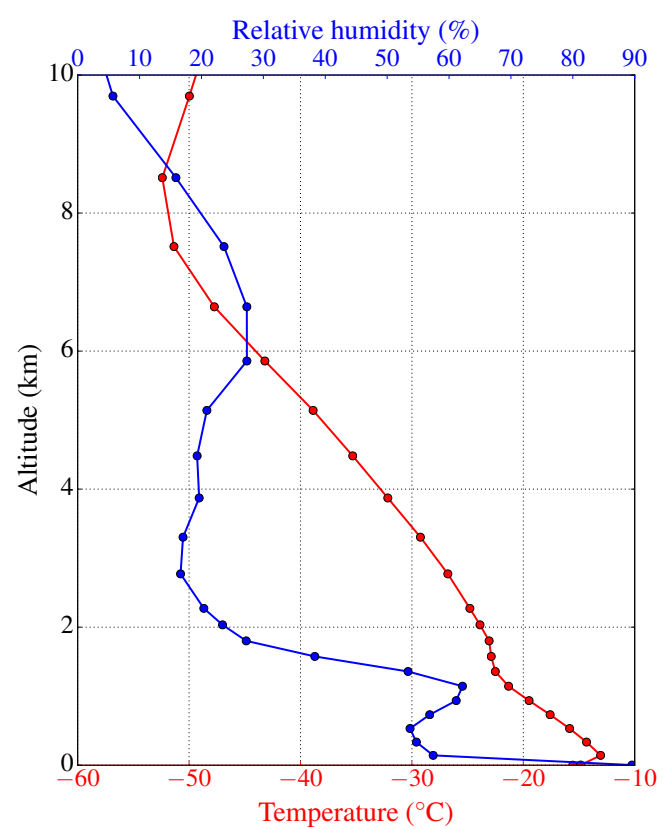

Figure 11. ERA-Interim profiles of temperature and humidity on 21 February 2015, 00:00 UTC. For the sake of clarity, the profile is shown up to $10 \mathrm{~km}$ only, but the reanalysis used for the radiative transfer calculations actually extends up to $46.2 \mathrm{~km}$.

spectral extinction and absorption coefficients of ice clouds are taken from the parameterization of cirrus clouds of Yang et al. (2005). The model is run at $1 \mathrm{~cm}^{-1}$ spectral resolution and multiple scattering is accounted for using the discrete ordinates method (Stamnes et al., 1988) with 32 beams.

\subsection{Results}

\subsubsection{Winter clear-sky experiment}

The ERA-Interim vertical profiles of temperature and humidity at 00:00 are shown in Fig. 11. The temperature close to the surface was $-15^{\circ} \mathrm{C}$ and the air was relatively dry, except for the first $2 \mathrm{~km}$. No clouds were observed during the measurements during which 11 FIRR sequences were acquired. Figure 12 shows the radiances measured with the FIRR along with the results of MODTRAN simulations. The sensitivity of the simulations to atmospheric inputs was estimated by adding a $\pm 1 \mathrm{~K}$ vertically uniform offset to the temperature profile or by perturbing the specific humidity by $\pm 10 \%$.

The standard deviation of the measured radiances is less than $0.02 \mathrm{~W} \mathrm{~m}^{-2} \mathrm{sr}^{-1}$ for all bands except for the $30-50 \mu \mathrm{m}$ band, which is close to the resolution obtained in the laboratory $\left(0.015 \mathrm{~W} \mathrm{~m}^{-2} \mathrm{sr}^{-1}\right)$. This confirms very stable clearsky conditions during the experiment and provides an assessment of FIRR measurements' quality in environmental conditions. In particular, the presence of clouds, even very thin, would have resulted in significant variations of the radiance in the $10-12 \mu \mathrm{m}$ band. The fact that simulations and 


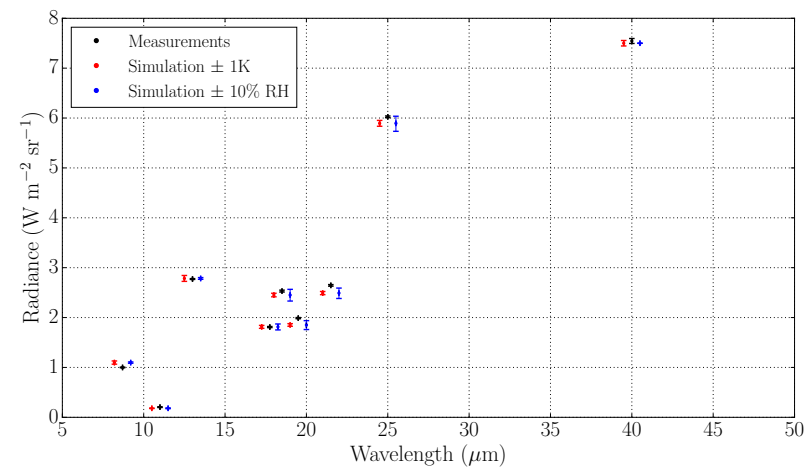

Figure 12. Radiances measured with the FIRR and simulated with MODTRAN for the 21 February 2015 night experiment. Blue error bars correspond to simulations with temperature profiles offset by $\pm 1 \mathrm{~K}$. Red error bars correspond to simulations with specific humidity profiles offset by $\pm 10 \%$.

measurements coincide so well in all bands suggests that the atmospheric reanalysis, the model and measurements are all consistent and of good quality. This provides a successful radiative closure experiment for clear-sky conditions (e.g., Delamere et al., 2010; Fox et al., 2015). The high sensitivity of the simulations to specific humidity in F-IR bands (except $30-50 \mu \mathrm{m}$ that is saturated) shows that the humidity profile must be precise with more than $5 \%$ accuracy. It also points out that the FIRR resolution is sufficient to discriminate between humidity profiles that differ by a few percent in a very dry atmosphere. The simulations nevertheless show an apparent negative bias in the F-IR, which is likely to be due to an erroneous water vapor profile. On the contrary, the results of the T-IR bands between 10 and $14 \mu \mathrm{m}$, which are sensitive to the whole atmospheric profile, ensure that the temperature profile is correct. The very low radiance measured in the 10$12 \mu \mathrm{m}$ band, which corresponds to a brightness temperature of $-125^{\circ} \mathrm{C}$, matches the simulation very well. It proves the quality of the calibration procedure, even when radiance is extrapolated far below the calibration BBs' radiances. As for the observed bias in the 7.9-9.5 $\mu \mathrm{m}$ band, it can hardly be explained by errors on the water vapor or temperature profiles. Based on a series of tests, it is rather likely the result of erroneous profiles of aerosols which were chosen somehow arbitrarily. Overall, these results are very encouraging for further investigation of the water cycle in the Arctic.

\subsubsection{Winter cloudy-sky experiment}

Figure 13 shows the variations of the brightness temperature in all FIRR bands during the series of measurements taken on 21 February 2015. Before 14:30 and after 18:00, all temperatures are within a range of approximately $10^{\circ} \mathrm{C}$, which is the signature of a cloud cover with sufficient optical depth. In between, the brightness temperatures show great variations as a result of cloud cover variations because the atmosphere

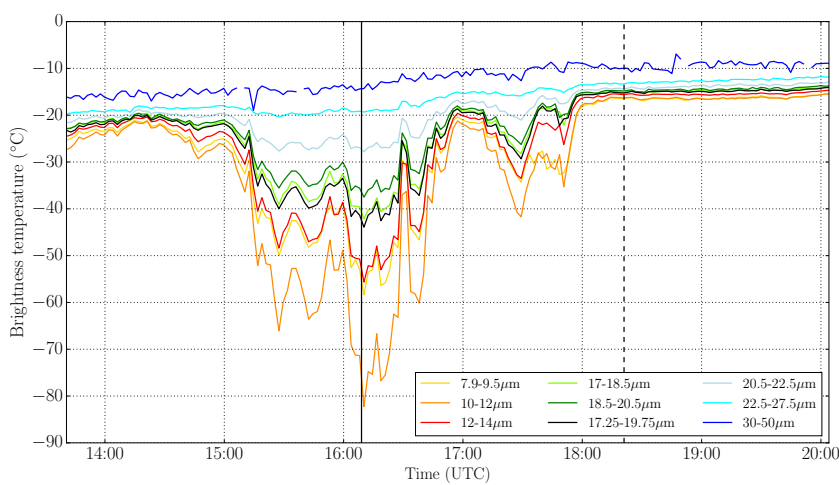

Figure 13. Time series of FIRR brightness temperatures for the 21 February 2015 experiment. The vertical lines indicate when the measurements shown in Fig. 14 were taken.

becomes more transparent. These variations are visible in all bands except the $30-50 \mu \mathrm{m}$ band because the latter is saturated by the atmosphere emission below the clouds and does not actually see the clouds. Around 16:10, the sky is nearly perfectly clear and the brightness temperatures reach a minimum.

The radiances measured by the FIRR were compared to MODTRAN simulations. For the simulations, the ERAInterim profiles at 18:00 were used with an ice cloud layer lying between 2.3 and $3.8 \mathrm{~km}$. A series of simulations were performed, with cloud optical depth $\tau$ ranging from 0.1 to 40 and cloud particles effective diameter $d_{\text {eff }}$ ranging from 3 to $250 \mu \mathrm{m}$. The 16:10 FIRR measurement (hereafter referred to as the thin cloud measurement) is shown in Fig. 14. The corresponding MODTRAN simulation that best fits the measurements is shown as well. The latter corresponds to an optical depth of 0.3 and an effective diameter of $20 \mu \mathrm{m}$, which minimizes the mean square deviation with regards to the observations (Blanchard, 2011). The 18:20 FIRR measurement (hereafter referred as thick cloud measurement) is also shown in Fig. 14 along with its corresponding optimal simulation, obtained for $\tau=12.5$ and $d_{\mathrm{eff}}=40 \mu \mathrm{m}$. The changes in atmospheric radiances observed with the FIRR are very well captured by the simulations in all bands. FIRR radiance increase in the $30-50 \mu \mathrm{m}$ band for the thick cloud is not simulated because a single ERA-Interim profile is used for both simulations while near surface temperature actually increased between both measurements. The retrieved optical depths are consistent with cloud cover visual observations.

The optimization procedure applied to the clear and cloudy sky cases was applied to all measurements taken from 16:10 to 20:30. The time series of the retrieved optical depth and effective diameter is shown in Fig. 15. This highlights the increase of optical depth with a marked transition around 18:00 as expected from the brightness temperatures. The effective diameter is very noisy and can hardly be compared to visual observations. The variations nevertheless seem more consis- 


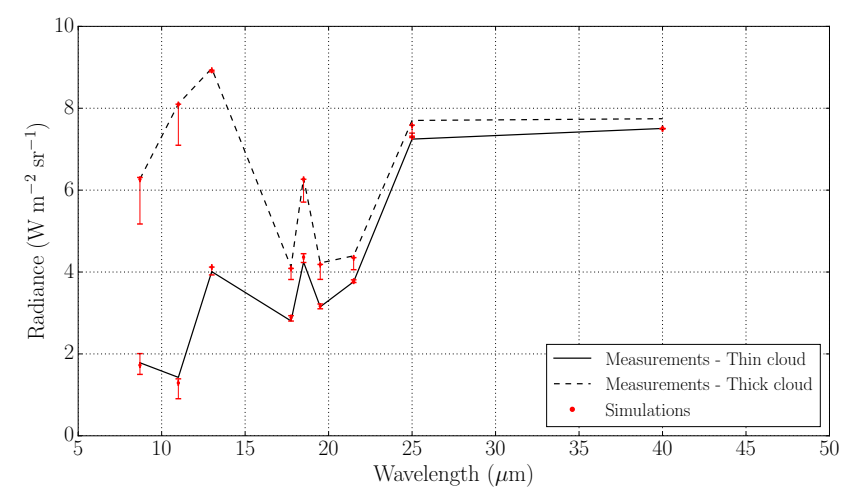

Figure 14. Radiances measured with the FIRR and simulated with MODTRAN for the 21 February 2015 experiment. Two cases are shown with different cloud covers. The thin cloud simulation corresponds to a cloud between 2.3 and $3.8 \mathrm{~km}$ with $\tau=0.3$ and $d_{\text {eff }}=$ $20 \mu \mathrm{m}$ (16:09 UTC) and the thick cloud simulation corresponds to a cloud between 2.3 and $3.8 \mathrm{~km}$ with $\tau=12.5$ and $d_{\mathrm{eff}}=40 \mu \mathrm{m}$ (18:21 UTC). Error bars indicate the range of radiances obtained for $d_{\text {eff }}$ varying from 3 to $250 \mu \mathrm{m}$.

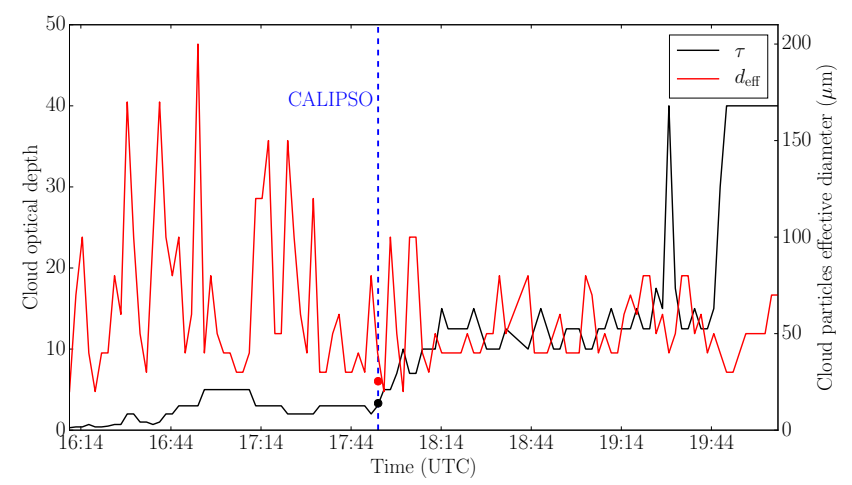

Figure 15. Time series of optical depth and effective diameter retrieved from FIRR measurements performed on 21 February 2015. The values retrieved from CALIPSO instruments $33 \mathrm{~km}$ east of the measurement site are indicated by large dots.

tent after 18:15 than before where the variations are physically irrelevant. The increase after 19:50 is also consistent with the observation of light precipitation at the end of the experiment. A CALIPSO (Cloud Aerosol Lidar and Infrared Pathfinder Satellite Observations) (Winker et al., 2003) overpass at 17:53, $33 \mathrm{~km}$ east of the measurement site, provides useful data for evaluation of the FIRR. Lidar profiles show a cloud with $\tau=3.32$ and the retrieval algorithm based on IR radiances suggests that $d_{\text {eff }}=25 \mu \mathrm{m}$. These values are shown in Fig. 15 and are consistent with the values retrieved by the FIRR. It seems that the optical depth retrieval works better for thin clouds, while effective diameter retrieval is more consistent for thick clouds. These results are in agreement with the theoretical findings of Yang (2003). A similar method was used by Palchetti et al. (2015) to retrieve ice cloud properties on the Antarctic Plateau.

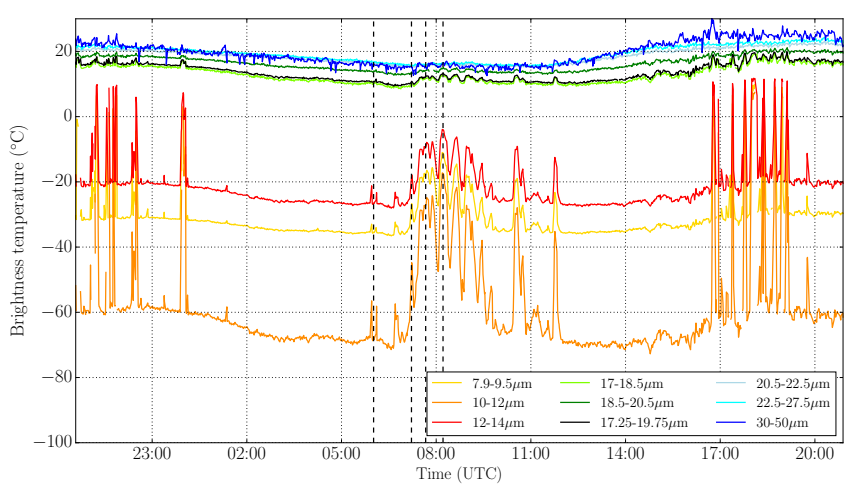

Figure 16. Time series of FIRR brightness temperatures for the 2 July 2015 experiment. Vertical dashed lines indicate when the four measurements shown in Fig. 17 were taken.

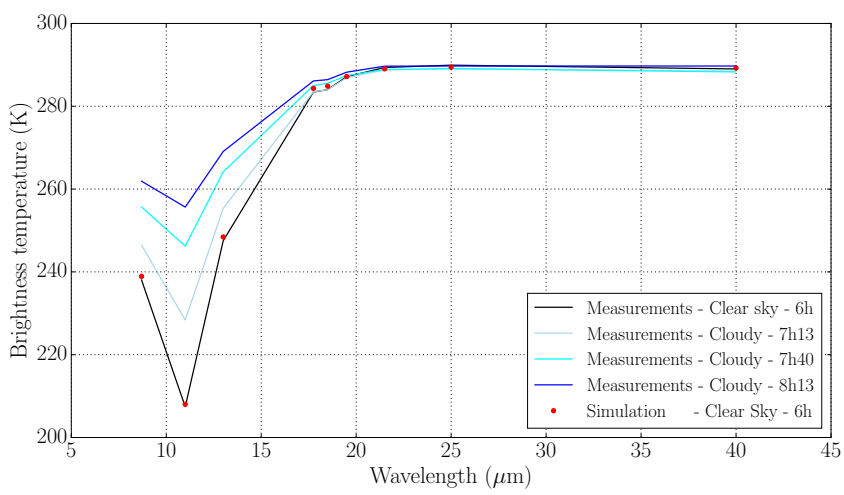

Figure 17. Brightness temperatures measured with the FIRR during the 2 July 2015 experiment. Four cases are shown with different cloud covers. They are also reported in Fig. 16. The MODTRAN simulation corresponding to the clear-sky conditions is indicated by red dots.

\subsubsection{Summer experiment}

The third experiment presented in this paper was performed in conditions very different from the previous ones with the intent to characterize the FIRR performances in relatively warm and humid atmospheres. Figure 16 shows the time series of brightness temperatures for this $24 \mathrm{~h}$ experiment. Sky pictures were taken every $30 \mathrm{~s}$ to provide qualitative information about the scene observed by the FIRR. The T-IR bands show large variations corresponding to clouds crossing the field of view of the FIRR. Narrow peaks at the beginning and at the end of the series correspond to small-scale cumulus, while the broader peak around 08:00 corresponds to the presence of a larger scale stratocumulus. The narrow peak around noon is concomitant with the presence of a cirrus. FIR bands show much smaller variations because the signal from the clouds is mostly attenuated by the warm and humid atmosphere below. Clear-sky periods (e.g., 02:00-05:00) show the high repeatability of the measurements characterized by a resolution of $0.1-0.2 \mathrm{~K}$ in all bands except the 30 
$50 \mu \mathrm{m}$ band. The latter exhibits the noisiest signal because it is sensitive to the BB enclosure temperature and humidity variations rather than actual atmospheric radiance variations.

Figure 17 shows the measured spectral brightness temperatures for four different sky conditions with nearly constant temperature and water vapor profiles according to RUC reanalysis. The brightness temperature increases much more in the T-IR than in the F-IR, pointing out the relative lack of interest of F-IR measurements in midlatitude summer atmospheres. The MODTRAN simulation based on RUC profiles at 06:00 perfectly matches the observations for clear-sky conditions, proving the quality of FIRR measurements in these singular conditions.

\section{Discussion and conclusions}

The radiometric performances of the FIRR were characterized through laboratory and in situ experiments and both approaches show very consistent results. With a value close to $0.02 \mathrm{~W} \mathrm{~m}^{-2} \mathrm{sr}^{-1}$, the FIRR radiometric resolution is much lower than the $0.1 \mathrm{~W} \mathrm{~m}^{-2} \mathrm{sr}^{-1}$ required for the TICFIRE mission (Blanchet et al., 2011). The current resolution is nevertheless the result of extensive data processing which takes advantage of pixels' spatial averaging and use of nonilluminated pixels. As the TICFIRE is meant to be an imager, spatial averaging will be limited. In addition, since the optics and detector of TICFIRE will be different than those of the FIRR, it is hazardous to apply FIRR radiometric characteristics to TICFIRE. However, it has been shown that spatial averaging over a reduced number of pixels, as well as temporal averaging, could improve TICFIRE radiometric performances. All in all, a trade will have to be made at the processing level between spatial and radiometric resolution, depending on the main objective of the TICFIRE mission.

The current FIRR resolution is sufficient to detect very small humidity variations in a dry atmosphere and could provide column water vapor retrievals with reduced uncertainties compared to other instruments like AIRS (Tobin et al., 2006) or REFIR-PAD (Bianchini et al., 2011) that provide $5-10 \%$ uncertainties on water vapor profiles. Comparison of FIRR-retrieved clouds' properties with CALIPSO data also suggests that the FIRR is an adequate tool to detect and characterize ice clouds, which is its primary mission. Nevertheless, the latter point could not be evaluated in more detail in this study due to the lack of adequate data. The retrieval algorithm used in this study and based on a least squares method is meant to be a preliminary illustration of the FIRR capabilities. It does not pretend to reach a specific level of accuracy. A rigorous evaluation would require collocated profiles of clouds properties and radiosoundings as presented in e.g., Blanchard (2011). In addition, the impact of cloud particles size distribution, shape and aspect ratios was not investigated here while these parameters are known to be critical factors for clouds' radiative properties (Chiriaco et al.,
2004; Baran, 2007; Maestri et al., 2014). A complete radiative closure experiment in the F-IR in cloudy conditions thus appears much more complicated than the experiment presented here for clear-sky conditions. The development of an appropriate retrieval algorithm is the next step for FIRR applications with expected instrument deployment at Eureka, Nunavut (Canada), and Barrow, Alaska (USA), in dedicated experimental sites in the next years. At these very cold Arctic locations, the data quality is expected to be better than in the present paper because the difference between $A B B$ and sky temperatures will be minor, enabling better calibration. Also, the data deterioration due to reduced transmittance of the air path between the calibration BBs and the FIRR detector should be much less in such cold and dry conditions with probable positive impact on the FIRR sensitivity in the $30-50 \mu \mathrm{m}$ band.

In an airborne or satellite configuration, downwardlooking FIRR measurements would also be very sensitive to the surface emissivity and temperature, especially in dry regions where atmospheric transmittance exceeds $50 \%$ in most spectral bands (Fig. 2b). FIRR measurements could help fill a gap in the spectral characterization of the Earth's surface emissivities, which are so far poorly constrained by observations in the F-IR (Feldman et al., 2014). This could also improve climate simulations in the polar regions, which are known to be sensitive to snow surface emissivity (Chen et al., 2014). Practically, for a snow surface at $-30^{\circ} \mathrm{C}$, a change of emissivity of 0.02 would result in a change of radiance at the top of atmosphere larger than the FIRR radiometric resolution for most FIRR bands, highlighting the potential of the instrument for such an application.

The FIRR novelty largely lies in its ability to probe radiation in the F-IR, an underexplored region of the Earth spectrum. The measurements presented in this paper already point out the FIRR capabilities in this remote spectral region. Indeed, with a sensitivity beyond $20 \mu \mathrm{m}$ nearly as high as in the T-IR, the radiometric performances are very satisfying and promising for future detection and characterization of ice clouds in the Arctic. Further effort will be put on the development of an appropriate retrieval algorithm for cloud properties that will be evaluated with regards to other reference instruments. These preliminary results nevertheless represent a substantial step toward the TICFIRE mission, whose design is currently being discussed with industrial partners at the Canadian Space Agency.

\section{Data availability}

The data used in this study are available upon request from the authors (libois.quentin@uqam.ca).

Author contributions. Q. Libois, L. Ivanescu, L. Coursol, L. Pelletier and F. Barbero participated to the laboratory and in situ experiments. Q. Libois and C. Proulx developed the calibration algorithm. Q. Libois and Y. Bouzid performed the radiative transfer 
simulations. Q. Libois prepared the manuscript with contributions from the other authors.

Acknowledgements. The authors are grateful to B. J. Drouin and an anonymous reviewer for helping to improve this manuscript. We also thank the editor for supporting this work. This research was funded jointly by the Canadian Space Agency (CSA) through the FAST program and by NETCARE, the Canadian Network on Climate and Aerosols through the Climate Change and Atmospheric Research (CCAR) program at NSERC. The authors are grateful to CSA for providing resources and logistic support on the development of the FIRR instrument. We are very grateful to LR Tech Inc. for their support during the FIRR laboratory characterization performed in their facilities.

Edited by: B. Kahn

\section{References}

Baran, A. J.: The impact of cirrus microphysical and macrophysical properties on upwelling far-infrared spectra, Q. J. Roy. Meteor. Soc., 133, 1425-1437, doi:10.1002/qj.132, 2007.

Berk, A., Bernstein, L. S., and Robertson, D. C.: MODTRAN: A moderate resolution model for LOWTRAN, Tech. rep., DTIC Document, 1987.

Best, F. A., Revercomb, H. E., Knuteson, R. O., Tobin, D. C., Dedecker, R. G., Dirkx, T. P., Mulligan, M. P., Ciganovich, N. N., and Te, Y.: Traceability of absolute radiometric calibration for the Atmospheric Emitted Radiance Interferometer (AERI), in: Proceedings of the Year 2003 Conference on Characterization and Radiometric Calibration for Remote Sensing, 15-18 September 2003, Utah State University, Space Dynamics Laboratory, Logan, Utah, 2003.

Bianchini, G. and Palchetti, L.: The REFIR-PAD farinfrared Fourier transform spectroradiometer, OSA, doi:10.1364/FTS.2011.FMC4， ISBN: 978-1-55752-914-5, 2011.

Bianchini, G., Palchetti, L., Muscari, G., Fiorucci, I., Di Girolamo, P., and Di Iorio, T.: Water vapor sounding with the far infrared REFIR-PAD spectroradiometer from a high-altitude groundbased station during the ECOWAR campaign, J. Geophys. Res., 116, D02310, doi:10.1029/2010JD014530, 2011.

Blanchard, Y.: Analyse du potentiel de la radiométrie infrarouge thermique pour la caractérisation des nuages de glace en Arctique, $\mathrm{PhD}$ thesis, Université de Sherbrooke, 160 pp., ISBN: 9780494832653, 2011.

Blanchard, Y., Royer, A., O'neill, N. T., and Blanchet, J.-P.: Retrieving cloud optical depth and ice particle size using thermal and Far infrered radiometry in an Arctic environment, 3, III-849III-852, IEEE, doi:10.1109/IGARSS.2009.5417902, 2009.

Blanchard, Y., Pelon, J., Eloranta, E. W., Moran, K. P., Delanoë, J., and Sèze, G.: A Synergistic Analysis of Cloud Cover and Vertical Distribution from A-Train and Ground-Based Sensors over the High Arctic Station Eureka from 2006 to 2010, J. Appl. Meteorol. Clima., 53, 2553-2570, doi:10.1175/JAMC-D-14-0021.1, 2014.
Blanchet, J.-P. and Girard, E.: Arctic 'greenhouse effect', Nature, 371, 383-383, doi:10.1038/371383a0, 1994.

Blanchet, J.-P. and Girard, E.: Water vapor-temperature feedback in the formation of continental Arctic air: its implication for climate, Sci. Total Environ., 160-161, 793-802, doi:10.1016/00489697(95)04412-T, 1995.

Blanchet, J.-P., Royer, A., Châteauneuf, F., Bouzid, Y., Blanchard, Y., Hamel, J.-F., de Lafontaine, J., Gauthier, P., O’Neill, N. T., Pancrati, O., and Garand, L.: TICFIRE: a far infrared payload to monitor the evolution of thin ice clouds, $8176,81761 \mathrm{~K}-81761 \mathrm{~K}-$ 11, doi:10.1117/12.898577, 2011.

Canas, T. A., Murray, J. E., and Harries, J. E.: Tropospheric airborne Fourier transform spectrometer (TAFTS), 3220, 91-102, doi:10.1117/12.301139, 1997.

Chen, X., Huang, X., and Flanner, M. G.: Sensitivity of modeled far-IR radiation budgets in polar continents to treatments of snow surface and ice cloud radiative properties, Geophys. Res. Lett., 41, 6530-6537, doi:10.1002/2014GL061216, 2014.

Chiriaco, M., Chepfer, H., Noel, V., Delaval, A., Haeffelin, M., Dubuisson, P., and Yang, P.: Improving Retrievals of Cirrus Cloud Particle Size Coupling Lidar and Three-Channel Radiometric Techniques, Mon. Weather Rev., 132, 1684-1700, doi:10.1175/1520-0493(2004)132<1684:IROCCP>2.0.CO;2, 2004.

Cimini, D., Nasir, F., Westwater, E., Payne, V., Turner, D., Mlawer, E., Exner, M., and Cadeddu, M.: Comparison of Ground-Based Millimeter-Wave Observations and Simulations in the Arctic Winter, IEEE Geosci. Remote S., 47, 3098-3106, doi:10.1109/TGRS.2009.2020743, 2009.

Clough, S. A., Iacono, M. J., and Moncet, J.-L.: Line-byline calculations of atmospheric fluxes and cooling rates: Application to water vapor, J. Geophys. Res., 97, 15761, doi:10.1029/92JD01419, 1992.

Comiso, J. C.: Warming Trends in the Arctic from Clear Sky Satellite Observations, J. Climate, 16, 3498-3510, doi:10.1175/15200442(2003)016<3498:WTITAF>2.0.CO;2, 2003.

Curry, J.: On the Formation of Continental Polar Air, J. Atmos. Sci., 40, 2278-2292, doi:10.1175/15200469(1983)040<2278:OTFOCP>2.0.CO;2, 1983.

Curry, J. A., Schramm, J. L., Rossow, W. B., and Randall, D.: Overview of Arctic Cloud and Radiation Characteristics, J. Climate, 9, 1731-1764, doi:10.1175/15200442(1996)009<1731:OOACAR>2.0.CO;2, 1996.

Dee, D. P., Uppala, S. M., Simmons, A. J., Berrisford, P., Poli, P., Kobayashi, S., Andrae, U., Balmaseda, M. A., Balsamo, G., Bauer, P., Bechtold, P., Beljaars, A. C. M., van de Berg, L., Bidlot, J., Bormann, N., Delsol, C., Dragani, R., Fuentes, M., Geer, A. J., Haimberger, L., Healy, S. B., Hersbach, H., Hólm, E. V., Isaksen, L., Kållberg, P., Köhler, M., Matricardi, M., McNally, A. P., Monge-Sanz, B. M., Morcrette, J.-J., Park, B.-K., Peubey, C., de Rosnay, P., Tavolato, C., Thépaut, J.-N., and Vitart, F.: The ERA-Interim reanalysis: configuration and performance of the data assimilation system, Quarterly Journal of the Royal Meteorological Society, 137, 553-597, doi:10.1002/qj.828, 2011.

Delamere, J. S., Clough, S. A., Payne, V. H., Mlawer, E. J., Turner, D. D., and Gamache, R. R.: A far-infrared radiative closure study in the Arctic: Application to water vapor, J. Geophys. Res., 115, D17106, doi:10.1029/2009JD012968, 2010. 
Delanoë, J. and Hogan, R. J.: Combined CloudSat-CALIPSOMODIS retrievals of the properties of ice clouds, J. Geophys. Res., 115, D00H29, doi:10.1029/2009JD012346, 2010.

Eastman, R. and Warren, S. G.: Arctic Cloud Changes from Surface and Satellite Observations, J. Climate, 23, 4233-4242, doi:10.1175/2010JCLI3544.1, 2010.

Feldman, D. R., Collins, W. D., Pincus, R., Huang, X., and Chen, X.: Far-infrared surface emissivity and climate, P. Natl. Acad. Sci., 111, 16297-16302, doi:10.1073/pnas.1413640111, 2014.

Fox, C., Green, P. D., Pickering, J. C., and Humpage, N.: Analysis of far-infrared spectral radiance observations of the water vapor continuum in the Arctic, J. Quant. Spectrosc. Ra., 155, 57-65, doi:10.1016/j.jqsrt.2015.01.001, 2015.

Grenier, P. and Blanchet, J.-P.: Investigation of the sulphateinduced freezing inhibition effect from CloudSat and CALIPSO measurements, J. Geophys. Res., 115, D22205, doi:10.1029/2010JD013905, 2010.

Grenier, P., Blanchet, J., and Munoz-Alpizar, R.: Study of polar thin ice clouds and aerosols seen by CloudSat and CALIPSO during midwinter 2007, J. Geophys. Res., 114, D09201, doi:10.1029/2008JD010927, 2009.

Harries, J., Carli, B., Rizzi, R., Serio, C., Mlynczak, M., Palchetti, L., Maestri, T., Brindley, H., and Masiello, G.: The Far-infrared Earth, Rev. Geophys., 46, RG4004, doi:10.1029/2007RG000233, 2008.

Jouan, C., Girard, E., Pelon, J., Gultepe, I., Delanoë, J., and Blanchet, J.-P.: Characterization of Arctic ice cloud properties observed during ISDAC, J. Geophys. Res., 117, D23207, doi:10.1029/2012JD017889, 2012.

Kahl, J. D., Charlevoix, D. J., Zaftseva, N. A., Schnell, R. C., and Serreze, M. C.: Absence of evidence for greenhouse warming over the Arctic Ocean in the past 40 years, Nature, 361, 335337, doi:10.1038/361335a0, 1993.

Knuteson, R. O., Revercomb, H. E., Best, F. A., Ciganovich, N. C., Dedecker, R. G., Dirkx, T. P., Ellington, S. C., Feltz, W. F., Garcia, R. K., Howell, H. B., Smith, W. L., Short, J. F., and Tobin, D. C.: Atmospheric Emitted Radiance Interferometer. Part I: Instrument Design, J. Atmos. Ocean. Tech., 21, 1763-1776, doi:10.1175/JTECH-1662.1, 2004.

Legrand, M., Pietras, C., Brogniez, G., Haeffelin, M., Abuhassan, N. K., and Sicard, M.: A High-Accuracy Multiwavelength Radiometer for In Situ Measurements in the Thermal Infrared. Part I: Characterization of the Instrument, J. Atmos. Ocean. Tech., 17, 1203-1214, doi:10.1175/15200426(2000)017<1203:AHAMRF>2.0.CO;2, 2000.

Maestri, T., Rizzi, R., Tosi, E., Veglio, P., Palchetti, L., Bianchini, G., Di Girolamo, P., Masiello, G., Serio, C., and Summa, D.: Analysis of cirrus cloud spectral signatures in the far infrared, J. Quant. Spectrosc. Ra., 141, 49-64, doi:10.1016/j.jqsrt.2014.02.030, 2014.

Mariani, Z., Strong, K., Wolff, M., Rowe, P., Walden, V., Fogal, P. F., Duck, T., Lesins, G., Turner, D. S., Cox, C., Eloranta, E., Drummond, J. R., Roy, C., Turner, D. D., Hudak, D., and Lindenmaier, I. A.: Infrared measurements in the Arctic using two Atmospheric Emitted Radiance Interferometers, Atmos. Meas. Tech., 5, 329-344, doi:10.5194/amt-5-329-2012, 2012.

McCleese, D. J., Schofield, J. T., Taylor, F. W., Calcutt, S. B., Foote, M. C., Kass, D. M., Leovy, C. B., Paige, D. A., Read, P. L., and Zurek, R. W.: Mars Climate Sounder: An investigation of ther- mal and water vapor structure, dust and condensate distributions in the atmosphere, and energy balance of the polar regions, J. Geophys. Res., 112, E05S06, doi:10.1029/2006JE002790, 2007.

Montanaro, M., Lunsford, A., Tesfaye, Z., Wenny, B., and Reuter, D.: Radiometric Calibration Methodology of the Landsat 8 ThermalInfrared Sensor, Remote Sensing, 6, 8803-8821, doi:10.3390/rs6098803, 2014.

Ngo Phong, L., Proulx, C., Oulachgar, H., and Châteauneuf, F.: Far infrared microbolometers for radiometric measurements of ice cloud, 9375, p. 93750G, doi:10.1117/12.2076219, 2015.

Niklaus, F., Decharat, A., Jansson, C., and Stemme, G.: Performance model for uncooled infrared bolometer arrays and performance predictions of bolometers operating at atmospheric pressure, Infrared Phys. Techn., 51, 168-177, doi:10.1016/j.infrared.2007.08.001, 2008.

Overland, J. E., Adams, J. M., and Bond, N. A.: Regional Variation of Winter Temperatures in the Arctic, J. Climate, 10, 821-837, doi:10.1175/1520-0442(1997)010<0821:RVOWTI>2.0.CO;2, 1997.

Palchetti, L., Barbis, A., Harries, J., and Lastrucci, D.: Design and mathematical modelling of the space-borne far-infrared Fourier transform spectrometer for REFIR experiment, Infrared Phys. Techn., 40, 367-377, doi:10.1016/S1350-4495(99)000262, 1999.

Palchetti, L., Belotti, C., Bianchini, G., Castagnoli, F., Carli, B., Cortesi, U., Pellegrini, M., Camy-Peyret, C., Jeseck, P., and Té, Y.: Technical note: First spectral measurement of the Earth's upwelling emission using an uncooled wideband Fourier transform spectrometer, Atmos. Chem. Phys., 6, 5025-5030, doi:10.5194/acp-6-5025-2006, 2006.

Palchetti, L., Bianchini, G., Carli, B., Cortesi, U., and Del Bianco, S.: Measurement of the water vapour vertical profile and of the Earth's outgoing far infrared flux, Atmos. Chem. Phys., 8, 2885 2894, doi:10.5194/acp-8-2885-2008, 2008.

Palchetti, L., Bianchini, G., Di Natale, G., and Del Guasta, M.: Far infrared radiative properties of water vapor and clouds in Antarctica, B. Am. Meteorol. Soc., 96, 1505-1518, doi:10.1175/BAMS-D-13-00286.1, 2015.

Proulx, C., Williamson, F., Allard, M., Baldenberger, G., Gay, D., Garcia-Blanco, S., Côté, P., Martin, L., Larouche, C., and Ilias, S.: The EarthCARE broadband radiometer detectors, in: SPIE Optical Engineering+ Applications, 74530S-74530S-11, International Society for Optics and Photonics, 2009.

Revercomb, H. E., Buijs, H., Howell, H. B., LaPorte, D. D., Smith, W. L., and Sromovsky, L. A.: Radiometric calibration of IR Fourier transform spectrometers: solution to a problem with the High-Resolution Interferometer Sounder, Appl. Optics, 27, 3210, doi:10.1364/AO.27.003210, 1988.

Rochette, L., Smith, W. L., Howard, M., and Bratcher, T.: ASSIST, Atmospheric Sounder Spectrometer for Infrared Spectral Technology: latest development and improvement in the atmospheric sounding technology, 7457, 745702-745702-9, doi:10.1117/12.829344, 2009.

Shaw, J. A., Nugent, P. W., Pust, N. J., Thurairajah, B., and Mizutani, K.: Radiometric cloud imaging with an uncooled microbolometer thermal infrared camera, Optics Express, 13, 5807, doi:10.1364/OPEX.13.005807, 2005.

Stamnes, K., Tsay, S.-C., Wiscombe, W., and Jayaweera, K.: Numerically stable algorithm for discrete-ordinate-method radiative 
transfer in multiple scattering and emitting layered media, Appl. Optics, 27, 2502-2509, doi:10.1364/AO.27.002502, 1988.

Stephens, G. L., Vane, D. G., Boain, R. J., Mace, G. G., Sassen, K., Wang, Z., Illingworth, A. J., O'Connor, E. J., Rossow, W. B., Durden, S. L., Miller, S. D., Austin, R. T., Benedetti, A., Mitrescu, C., and CloudSat Science Team, T.: THE CLOUDSAT MISSION AND THE A-TRAIN: A New Dimension of SpaceBased Observations of Clouds and Precipitation, B. Am. Meteorol. Soc., 83, 1771-1790, doi:10.1175/BAMS-83-12-1771, 2002.

Taylor, J. K., Revercomb, H. E., Buijs, H., Grandmont, F. J., Gero, P. J., Best, F. A., Tobin, D. C., Knuteson, R. O., LaPorte, D. D., Cline, R., Schwarz, M., and Wong, J.: The University of Wisconsin Space Science and Engineering Center Absolute Radiance Interferometer (ARI), 7857, 78570K-78570K-9, doi:10.1117/12.869581, 2010.

Tobin, D. C., Revercomb, H. E., Knuteson, R. O., Lesht, B. M., Strow, L. L., Hannon, S. E., Feltz, W. F., Moy, L. A., Fetzer, E. J., and Cress, T. S.: Atmospheric Radiation Measurement site atmospheric state best estimates for Atmospheric Infrared Sounder temperature and water vapor retrieval validation, J. Geophys. Res., 111, D09S14, doi:10.1029/2005JD006103, 2006.

Turner, D. D. and Mlawer, E. J.: The Radiative Heating in Underexplored Bands Campaigns, B. Am. Meteorol. Soc., 91, 911-923, doi:10.1175/2010BAMS2904.1, 2010.
Turner, D. D., Merrelli, A., Vimont, D., and Mlawer, E. J.: Impact of modifying the longwave water vapor continuum absorption model on community Earth system model simulations, J. Geophys. Res., 117, D04106, doi:10.1029/2011JD016440, 2012.

Wallace, K., Wright, N., Spilling, D., Ward, K., and Caldwell, M.: The broadband radiometer on the EarthCARE spacecraft, 7453, 74530H-74530H-8, doi:10.1117/12.825837, 2009.

Wang, X.: Recent Trends in Arctic Surface, Cloud, and Radiation Properties from Space, Science, 299, 1725-1728, doi:10.1126/science.1078065, 2003.

Winker, D. M., Pelon, J. R., and McCormick, M. P.: The CALIPSO mission: spaceborne lidar for observation of aerosols and clouds, 4893, 1-11, doi:10.1117/12.466539, 2003.

Yang, P.: Spectral signature of ice clouds in the far-infrared region: Single-scattering calculations and radiative sensitivity study, J. Geophys. Res., 108, 4569, doi:10.1029/2002JD003291, 2003.

Yang, P., Wei, H., Huang, H.-L., Baum, B. A., Hu, Y. X., Kattawar, G. W., Mishchenko, M. I., and Fu, Q.: Scattering and absorption property database for nonspherical ice particles in the near- through far-infrared spectral region, Appl. Optics, 44, 5512, doi:10.1364/AO.44.005512, 2005. 